\title{
Community Sustainability Planning as a Tool for Increased Environmental Sustainability: The Case of Two California Cities
}

\author{
William Riggs \\ PhD; Assistant Professor, CRP Cal Poly.
}

\author{
Henry Pontarelli \\ Principal, Lisa Wise Consulting.
}

\begin{abstract}
Based on their professional work, William Riggs and Henry Pontarelli argue that Community Sustainability Plans can achieve community reliance through a balance of social, economic, and ecological factors. They discuss their approach and take lessons from case studies in two California cities, Morro Bay and Monterey.
\end{abstract}

Sine ince the publication of the Bruntland Report (1987) and subsequent passing of greenhouse climate change regulations (such as AB32 and SB375 in California) cities around the globe have been keenly focused on achieving triple bottom line sustainability. Such analysis evaluates the economic, social and environmental implications of development (Brown, Marshall, \& Dillard, 2006). While in theory such a balance between social equity, economic prosperity, and ecological health presents a new paradigm for planning (Beatley, 1995; Berke, 2002; Knight \& Riggs, 2010), it also presents serious challenges in developing and applying innovative approaches to balancing the nexus.

This difficulty in implementing frameworks that support this dichotomy is especially important in coastal areas (Hilborn, 2007). Such areas have a reliance on the ecology fisheries as a part of the local economy and cultural identity, and therefore the balance among social, ecological, and economic factors is acute. Indicators and metrics have been established in recent years to measure and benchmark this relationship over time (Sethi, Riggs, \& Knapp, 2014)presenting data from 324 Alaskan communities over 1980-2010. These metrics provide an initial data set for descriptive analyses of fishing community status and for exploratory analyses to identify hypotheses for subsequent in-depth study of the socioecological dynamics of Alaskan fishing communities. Metrics were derived by collating information from publicly available databases and including information on fishing portfolios, fishing revenues, fishermen demographics, and fleet characteristics. As demonstration of the community metrics, we examine metric trends in detail for three communities but from a policy standpoint, there have been few frameworks established to achieve this balance (Evans, Joas, Sundback, \& Theobald, 2005; Lang et al., 2012).

This article argues that Community Sustainability Plans (CSPs) can be a tool to provide tangible policy that operationalizes the triple-bottom line approach. After a short introduction of our methodology, we provide an overview of how CSPs have developed. We then explore two California case studies that show how CSPs can offer a method of better achieving community resilience. These are discussed in the context of the aforementioned Bruntland framework, and offer lessons for practicing planners in moving toward such sustainability planning in their own cities.

\section{Community Sustainability Plans}

Community Sustainability Plans (CSP) are cited in the Magnuson-Stevens Fishery Conservation and Management Act ([MSA], 2007) as a requirement for communities that wish to remain eligible to participate in programs such as Individual Transferable Quota (ITQ) that was instituted in the federal trawl groundfish fishery in 2011. ITQ is considered a Limited Access Privilege Protocol (LAPP) program. The MSA is the overriding law for all federal fisheries in the United States. The groundfish fishery is valued at hundreds of millions of dollars on the West Coast and represents thousands of jobs, investment in physical infrastructure as well as a source of fresh, locally sourced seafood. Morro Bay and Monterey were heavily reliant on the trawl fishery beginning in the 1970s through the mid 2000s. Statewide drops in the trawl fishery began in the late 1990s and dropped to almost zero in both communities by 2006 and 2007 primarily due to regulation, rising costs, competition from inexpensive foreign imports, and loss and consolidation of processors. Some of the regulations that contributed to the decline of the Monterey and entire California trawl industry include:

- Federal Buy Back Program (1987) aimed at reducing effort by buying boats and permits back from willing sellers.

- Limited Entry Program (1994) that capped the number of vessels allowed to participate in the trawl fishery and imposed restrictions on the use and transfer of permits.

- Rockcod Conservation Area and Trawl Rockcod Conservation Area (2002) that extended the length of the West Coast and restricts activity on traditional trawl grounds. 
- Essential Fish Habitat (2006) restricted trawling in over 3.8 million acres off the Central Coast.

The decline of the trawl fishery was in many ways evidence of a high volume, large-scale business model that was no longer viable in the modern market. One of the key factors of the ITQ trawl program is that it allows fishermen to target groundfish using hook and line or traps, where in the past they had to use a trawl net. The modern trawl fleet has made great environmental advances, these methods are seen as generating less habitat disturbance and less bycatch. This enables a higher quality, lower volume approach. Such environmental accomplishments have not gone unnoticed, this summer (2014), the Marine Stewardship Council certified 12 species of groundfish, all traditionally landed in Morro Bay and Monterey. Also, the Monterey Bay Seafood Watch Program is moving several groundfish species from "Red" designation (avoid) to "Yellow" (good alternative) or "Green" (best choice).

While CSPs are required, the exercise was seen by the Cities of Morro Bay and Monterey as an opportunity to continue strategic planning for their working waterfronts and to better capitalize on their commercial fishing industries. These communities are keenly aware of the unique nature and value of their waterfronts that provide jobs, spur investment, fuel tourism, engage in marine stewardship, and provide a rich cultural heritage and identity.

CSPs are required for communities that wish to remain eligible to participate in ITQ, but the language in MSA is vague as to their construct and the specific information that Federal regulators are seeking,

". . to to be eligible to participate in a limited access privilege program to harvest fish, a fishing community shall .. . "develop and submit a community sustainability plan to the Pacific Fisheries Management Council (PFMC) and the Secretary that demonstrates how the plan will address the social development needs of coastal communities, including those that have not historically had the resources to participate in the fishery, for approval based on criteria developed by the Council that have been approved by the Secretary and published in the Federal Register" (MSA, 2007).

The language calls on communities to consider the dynamics of social performance, and Morro Bay and Monterey clearly achieved that objective, both devoting one full chapter to social dynamics and including social scientists on the CSP team, yet the passage does little to guide authors on details. It was the opinion of project managers in Morro Bay and Monterey that this may have been part of a more bottom-up approach that federal regulators have recently adopted in the groundfish ITQ fishery.

In the best case scenario, communities would use their CSP as a platform by which to help shape policy through the regional councils, in this case the Pacific Fisheries Management Council
(PFMC) - one of nine in the United States. For example, one of the communities, or Morro Bay, Monterey, and Half Moon Bay, which is currently working on a CSP, could provide a more compelling argument in support of electronic monitoring as an alternative to $100 \%$ human observer coverage or that bondscale funding was needed to address critical infrastructure needs if they approached the PFMC as a group and cited key CSP recommendations rather than a community without a formal "plan" or group of fishermen alone. In this case, federal regulators might also have a better picture of the more generalized needs of small communities in the ITQ program.

On one hand, a more bottom-up approach gives communities greater access in shaping policy, on the other hand, the ITQ program pushes responsibility and costs to the vessel and community level through $100 \%$ accountability, zero discards of rockfish and requirements of carrying a NMFS-trained observer on each trip and offloading at a NMFS-approved facility as well as requiring vessel owners to create and manage quota accounts. These responsibilities take a greater significance in small communities and for smaller operations, with less access to capital and other resources.

In the best sense, a flexible approach to the structure of a CSP bespeaks a more bi-directional approach to management by the Federal Government, enabling each community to fashion a CSP to meet their own unique objectives and giving communities a greater voice and vehicle for codifying needs and impacts. This may be more significant for smaller communities that are taking on a relatively greater burden and have less resources to express their needs to policy makers.

\section{Methodology}

We use a case approach to investigate CSPs as a model for sustainable coastal urbanism. The work relied heavily on input from the commercial fishing community and waterfront stakeholders, City staff and public officials in each jurisdiction, as well as historic data. These data include indicators, or categories of performance such as production and gross revenue, and metrics are the measures within the categories such as the landings by weight (pounds or tons), and earnings at the dock by dollar value. Such variables are consistent with the literature that supports adaptive use of sustainability indicators (Reed, Dougill, \& Baker, 2008; Reed, Fraser, \& Dougill, 2006). An example of indicators and metrics is provided in Table 1.

At the direction of the individual communities, we also evaluate critical infrastructure and services, as well as rents and wharfages. ${ }^{1}$ This is in contrast to more rigid regional approaches which may have arisen to certify sustainability practices for the financial marketplaces (Ballou, Heitger, \& Landes, 2006; Manetti \& Becatti, 2009; Nitkin \& Brooks, 1998).

\footnotetext{
${ }^{1}$ Wharfage is a fee levied by the City based on the amount of seafood landed or trucked to a tenant's facility.
} 


\begin{tabular}{|l|l|}
\hline \multicolumn{1}{|c|}{ Indicator } & \multicolumn{1}{c|}{ Metric } \\
\hline Production & Landings by Weight \\
\hline Revenue & Earnings at the Dock, Ex-Vessel Value, Price per Pound \\
\hline Diversity & Relative Species Mix \\
\hline Activity & Trips, Vessel IDs \\
\hline Employment & Number and Job Types \\
\hline Industry Landscape & $\begin{array}{l}\text { Presence and Condition of Critical Infrastructure and } \\
\text { Services }\end{array}$ \\
\hline Synergies & Resource Sharing Within and Across Industries \\
\hline Awareness & Level of Waterfront Tourism, Demand for Product \\
\hline Trends & Change in Metrics Over Time \\
\hline
\end{tabular}

Table 1: Community Sustainability Indicators

This is important since we use the cities Morro Bay and Monterey in California as our case studies. Morro Bay and Monterey are unique in that they provide a contextual look at a coastal village with reliance on a productive fishery and tourism in addition to other economic sectors, which balance the local economy. Both are extremely productive and have parallels in San Diego, Santa Barbara, Port San Luis, Half Moon Bay, and Fort Bragg in California and in Coos Bay and Newport in Oregon as well as in Seattle and Tacoma in Washington State. Both examples provide for differed levels of critical supportive services but also policy and community engagement that provide important lessons for sustainability planning in coastal communities.

In response to the requirements in the MSA, the CSPs also focused on social performance measures and relied on direct contact with commercial fishermen, related industry stakeholders, waterfront business owners, and civic leaders through personal interviews, site visits, and public meetings. The Consultant Team included two experts in social sciences with years of experience working in coastal communities. Given the unanimous approval by the Morro Bay and Monterey City Councils, the support from the commercial fishing communities and working waterfront stakeholders, the social component brought more tangibility and credibility to the work. In both cases, the communities began working on key recommendations; in Morro Bay a collaborative pursuit (City of Morro Bay and MBCFO) of the market demand of a boatyard and haulout facility and in Monterey, efforts at forming a community quota fund were initialized.

A robust analysis of the social dynamics of the commercial fishing industry within the working waterfront as well as the assessment of economic and environmental factors was also driven by the National Fish and Wildlife Foundation (NFWF), Fishery Innovation Fund grant. The grant also prioritizes the inclusion of fishermen in the sustainability planning process. NFWF is a public private partnership between NOAA and the Moore and Walton Family Foundations that, with some effort in the qualification and pursuit of the grant, provided the means to address an unfunded mandate in the MSA. NOAA makes policy for U.S. federal fisheries and is advised by NMFS which works closely with regional councils.

\section{The Case of Morro Bay and Monterey}

\section{Economic Performance}

Commercial fishing generates approximately $\$ 7$ million at the dock for fishermen in Monterey and Morro Bay every year (California Department of Fish \& Wildlife, 2014). In the State of California, commercial fishing generates approximately $\$ 200$ million annually and the West Coast of the United States (excluding Alaska) represents $\$ 500$ million at the docks and generates tens of thousands of jobs (NOAA-National Marine Fisheries Service, 2014).

In both communities, one of the strongest economic impacts of a working waterfront and commercial fishing industry was the synergy with tourism. In Monterey County, tourism generates $\$ 2$ billion in spending annually and over 22,000 jobs. More than half of the eight million tourists who come to Monterey County each year visit Fisherman's Wharf (Monterey County Business Council, 2012).

A 2007 opinion poll of over 800 California residents found that $71 \%$ "seek out and enjoy going to working waterfronts"

Figures 1 \& 2: Monterey facilities integrated with sales and tourism.
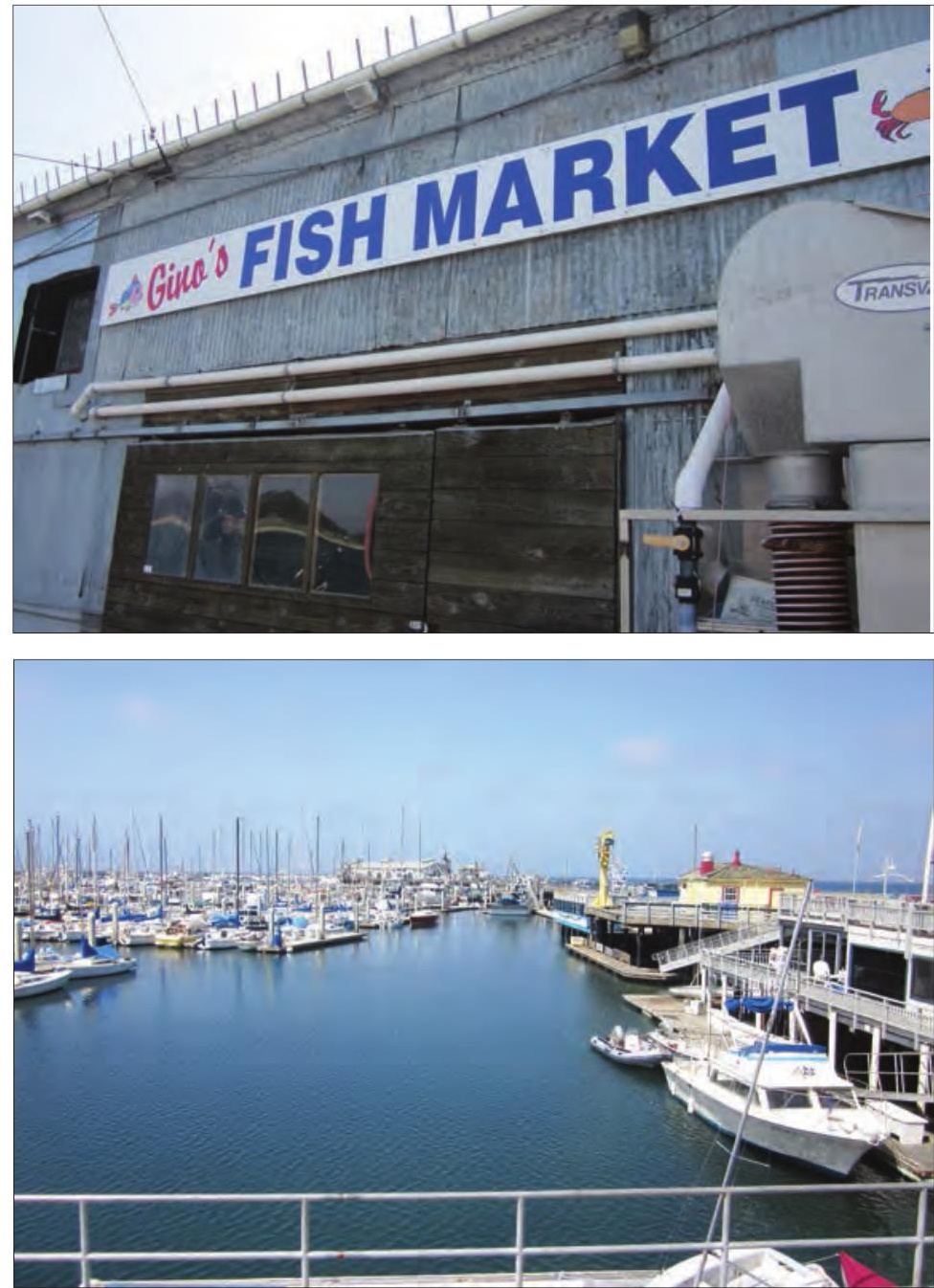
(Responsive Management, 2007, p. 57). Furthermore, in a 2008 survey of over 140 tourism professionals in Morro Bay, Monterey, and Crescent City, respondents gave, "tourism from having an active waterfront," a mean rating of 8.82 out of 10 in importance (Responsive Management, 2008, p. 17). In that same survey, tourism professionals indicated that, "having local, fresh seafood available was of great importance in attracting business to their community." Interviews conducted for the CSP effort suggest that the sentiments expressed in these reports have remained, and perhaps grown stronger, in favor of the interest in a working waterfront and access to fresh, local, sustainable seafood.

Another significant economic indicator of commercial fishing and working waterfront performance is employment. It is estimated that in Morro Bay approximately 195 jobs are generated on the boats, on the docks and in the County's only fish processing plant as a direct result of the commercial fishing industry. In Monterey County, approximately 720 jobs are generated processing squid and sardines from landings in Monterey and in Moss Landing. The processing plants in Monterey County were originally intended to process apricots and strawberries and would otherwise be idle and the workers, typically farmhands, benefit from the commercial fishing activity that is concentrated in the winter months when work in the field is slower. The synergies across industries, agriculture and commercial fishing, represent significant economic and social capabilities, the ability to form alliances with diverse partners as well as better access to inputs and improved profitability.

\section{Environmental Performance}

Environmental performance is one of the foundational components of a sustainable system. Of the thousands of species off the Central Coast, each of the approximately 25 species landed in Morro Bay and Monterey is regulated by state or federal law and carries strict reporting requirements. Upon each landing and the sale of fish, commercial fishermen and buyers are required to submit information, through a fish ticket, on the catch location, date, type of gear used, skipper name, vessel identification number, permit numbers, as well as weight, price and total earnings for each species. All of this data is aggregated and posted on the California Department of Fish and Wildlife website for public access. Transparency of activity on the water, as divulged through fish tickets, is prerequisite for sustainable outcomes.

Management measures for the top species landed in Morro Bay and Monterey are illustrated in Table 2.

Another indicator of environmental performance is improving stock status of key species as reported by federal and state agencies, which include Pacific swordfish, Chinook salmon, Widow rockfish, Bocaccio rockfish, Pacific cowcod, Petrale sole, Sablefish and Dover sole. Certification from third parties such as the Marine Stewardship Council (MSC) should also be considered as indicators of environmental performance. According to a recent study, in 2014, twelve groundfish species were certified by the MSC, all of which are currently and historically landed in Morro Bay and Monterey (NOAA Fisheries - West Coast Region, 2014).

The commercial fishing communities in Morro Bay and Monterey exhibit key environmental performance capabilities by engaging is a diversity of fisheries on a diversity of habitats with a diversity of gear types, reducing impacts on any single fish stock or habitat, as well as transparency through strict reporting requirements, regulatory measures that are guided by science and evaluated periodically, strict and extensive spatial closures, gear restrictions, and quota based management, all considered hallmarks of sustainability. Although many vulnerable species still require reduced exploitation to recover, the exploitation rates in a number of well studied ecosystems [like California] are below levels the models predict to be sustainable (Worm et al., 2009).

\section{Social Equity and Community}

Sustainability within coastal communities and their working waterfronts has frequently been examined in terms of economic

\begin{tabular}{|c|c|c|c|c|c|c|c|c|c|c|}
\hline $\begin{array}{l}\text { Table 2: Species in Morro Bay } \\
\text { and Monterey. }\end{array}$ & CPS & Crab & Nearshore & Salmon & $\begin{array}{l}\text { White } \\
\text { Seabass }\end{array}$ & Groundfish & $\begin{array}{l}\text { Callfornia } \\
\text { Halibut }\end{array}$ & $\begin{array}{l}\text { Pacific } \\
\text { Hagfish }\end{array}$ & $\begin{array}{c}\text { Highly } \\
\text { Migratory } \\
\text { Species }\end{array}$ & $\begin{array}{l}\text { Spot } \\
\text { Prawn }\end{array}$ \\
\hline Management Level & State/Fed & State & State/Fed & State/Fed & State/Fed & State/Fed & State & State & Fed & State \\
\hline Stock Assessment & $\cdot$ & & $\bullet$ & $\bullet$ & $\bullet$ & $\bullet$ & $\bullet$ & & $\cdot$ & \\
\hline \begin{tabular}{|l} 
Reporting \\
Requirements
\end{tabular} & • & $\bullet$ & $\bullet$ & • & • & • & • & $\bullet$ & • & • \\
\hline Spatial Closures & & & • & & & • & • & & • & • \\
\hline Catch Limits & $\bullet$ & & $\bullet$ & $\bullet$ & & $\bullet$ & $\bullet$ & & & \\
\hline Seasonal Closures & $\bullet$ & $\bullet$ & & $\bullet$ & $\bullet$ & & $\bullet$ & & $\bullet$ & $\bullet$ \\
\hline Gear Restrictions & & $\bullet$ & $\bullet$ & $\bullet$ & $\bullet$ & & $\bullet$ & $\bullet$ & & \\
\hline Sex/Size & & $\bullet$ & $\bullet$ & $\bullet$ & $\bullet$ & & $\bullet$ & & & \\
\hline Number of Vessels & $\bullet$ & & • & & & • & • & & & • \\
\hline Trap Limits & & $\bullet$ & & & & & & $\bullet$ & & $\bullet$ \\
\hline \begin{tabular}{|l} 
Quota-Based \\
Management
\end{tabular} & & & & & & • & & & & \\
\hline
\end{tabular}


or environmental standards. Less frequent are discussions of the role that relationships, communication, respect, social cohesion, trust, leadership, organization and perspective of the future play in determining the long-term viability of a commercial fishing community. Yet, the more cohesive and effective the leadership (respect, communication, shared knowledge), the larger and more capable a group can grow and the more complicated and sophisticated tasks it can accomplish. Specifically Morro Bay provides a window into how social performance can sustain or contribute to coastal communities.

Based on community input under the direction of a cultural anthropologist, the following social sustainability metrics have been identified as playing a significant role in Morro Bay and Monterey.

- Social cohesion

- Sense of identity

- Self organization

- Leadership

- Communication and education

- Intergenerational employment

For example, in Morro Bay, the fishing community has maintained a strong sense of social cohesion, self organization and leadership, as evidenced by the formation of the Morro Bay Commercial Fisherman's Organization (MBCFO) in 1974 and its current membership of over 100 members (Figure 3 ).

Social cohesion is also evidenced by the commercial fishing industry's strong relationships with City of Morro Bay staff and civic leaders, the aquaculture industry, local merchants, and with the Commercial Passenger Fishing Vessel (CPFV) fleet, skippers and deckhands switching back and forth. The fishing fleet also has strong ties to the academic community and has engaged in several collaborative research projects with California Polytechnic State University and the Bren School at University of California, Santa Barbara.

Figure 3: Membership in MBCFO.

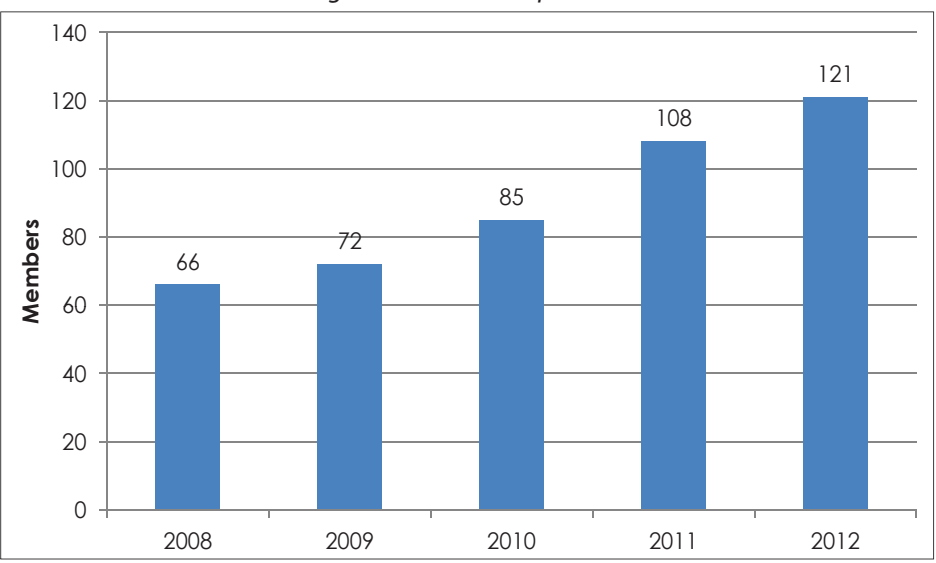

The fishing community has also shown effective communication capabilities, attracting support in the form of grant funding from the California Coastal Conservancy, National Fish and Wildlife Foundation, the Central Coast Joint Cable Fishery Liaison Committee, as well as Environmental Defense Fund and The Nature Conservancy. The recent formation and successes of the Central Coast Women for Fisheries, which includes the distribution of approximately 85 scholarships, is further evidence of the community's ability to self organize, attract funding, support fishermen and fishing families, and educate the general public. All of these factors enrich the lives of the participants and contribute to the identity of the community. Social performance sustains and is sustained by economic and environmental performance. The economic, social, and environmental systems are dependent on each other.

\section{Lessons for Policy and Practice}

Our work shows that value of using CSPs to improve total sustainability. For example in Morro Bay, at the behest of project managers and the fishing community, we focused on a handful of the highest priority needs of commercial fishermen. Those included, for example, a Boatyard and Haulout Facility with economic implications of potential increased employment opportunities and an income stream for the City, environmental implications of a greater ability for the City to remove derelict vessels that pose "spill" risks and threaten the fragile estuary as well as reduced greenhouse gas emissions as vessel owners can stay closer to home for their annual haulout and maintenance. Social implications include the community's greater control of outcomes, security for vessel owners that critical services are near, and an important connection of diverse user groups through a service required universally by vessel owners, fishermen, sailors, Coast Guard, and Harbor Patrol.

These findings however indicate another key lesson-flexibility and adaptability in sustainability planning is important. Community performance measures are "messy," as demonstrated in Figure 4, which shows gross earnings for the top 9 ports in California. If extended over time for a selection of fishing communities of different sizes and geographic locations, this would likely yield significant variability. Communities also have entropy based on size, scale, and stocks, and while they can be 'profiled' this snapshot can change with time, and economic or environmental shocks. Our goal is to use CSPs to mitigate the risk and create more resilience to these system shocks.

Furthermore we also show that indicators alone do not tell the story of sustainability. Consistent with what many social scientists have hypothesized, our cases illustrate a situation where community partnership can not only strengthen a fishery, it can improve the quality of indicators that benchmark it. Both of our cases illustrate this second factor.

Finally, we offer that if jurisdictions and industries can improve the quality of indicators while pursing sustainability, then it can also lead to future projection. Understanding of the factors 
Figure 4: Gross Earnings for the Top 9 Fishing Communities in California Based on Estimated Vessel Value in 2013 (EVV).

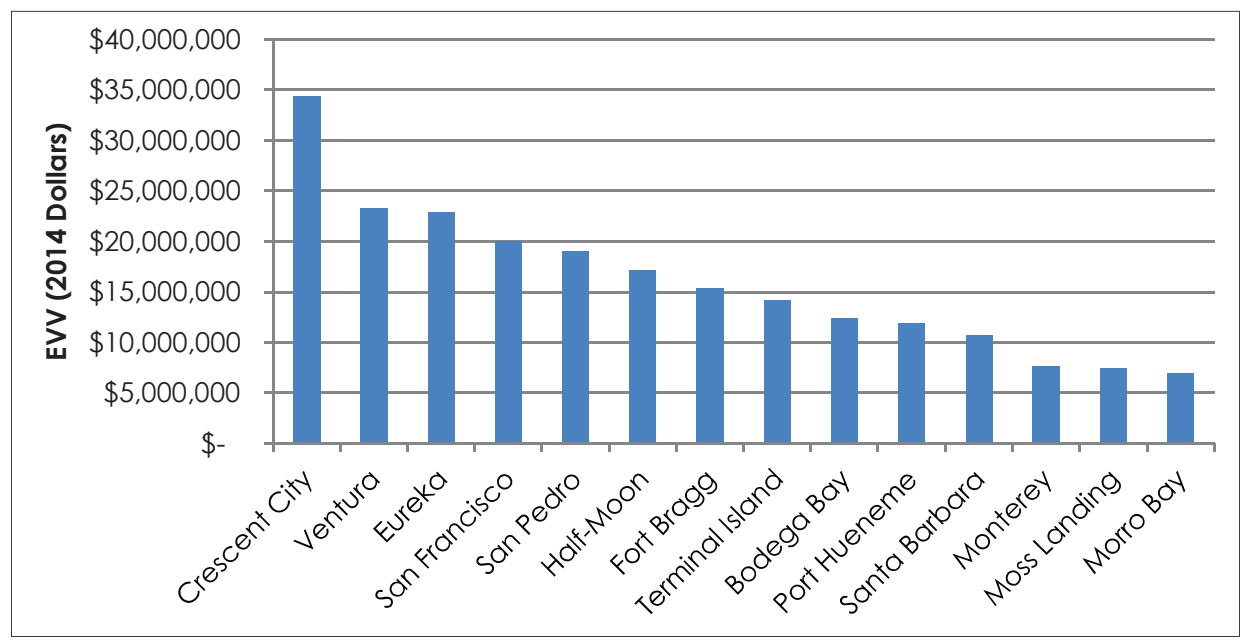

contributing to resilience can potentially suggest future policy actions to promote these factors if possible. A focal hypothesis this leads to is: communities with access to a greater diversity of fishing opportunities demonstrate less landings gross revenues variability and increased annual gross revenues, and the number of different fisheries for which citizens in a community own permits is related to land use growth.

To address this hypothesis, future research should extend our work and the work of others on metrics of association using geographic-based regression with Quantum GIS and other simulation tools. This will allow for the exploration of how land use changes and economic prosperity can contribute to downward trends in ecological productivity. Parallel research has been done on urban ecosystems and transportation choices but not focused on the economic and land use factors as they relate to coastal ecology (Waddell, 2002; Waddell, Ulfarsson, Franklin, \& Lobb, 2007). We hypothesize that there is a 'tipping point' at which communities experience a 'tragedy of the commons' and the economic productivity of the fishery begins to suffer based on the negative impacts of land use growth. It could lead to better tools for risk management and future fisheries policy.

\section{References}

Ballou, B., Heitger, D. L., \& Landes, C. E. (2006). The future of corporate sustainability reporting: A rapidly growing assurance opportunity. Journal of Accountancy, 202(6), 65-74.

Beatley, T. (1995). Planning and sustainability: The elements of a new (improved?) paradigm. Journal of Planning Literature, 9(4), 383-395.

Berke, P. R. (2002). Does sustainable development offer a new direction for planning? Challenges for the twenty-first century. Journal of Planning Literature, 17(1), 21-36.
Brown, D., Marshall, R. S., \& Dillard, J. F. (2006). Triple bottom line: A business metaphor for a social construct. Documents de Treball (Universitat Autònoma de Barcelona. Departament d'Economia de l'Empresa), 6(2), 1-29.

Brundtland, G. H. (1987). World commission on environment and development. Our Common Future, 8-9.

California Department of Fish and Wildlife. (2014). Commercial Fishery Data. Retrieved from https://www.dfg.ca.gov/marine/groundfishcentral/comdata.asp

Evans, B., Joas, M., Sundback, S., \& Theobald, K. (2005). Governing sustainable cities. London, England: Earthscan.

Hilborn, R. (2007). Moving to Sustainability by Learning from Successful Fisheries. AMBIO: A Journal of the $\mathrm{Hu}$ man Environment, 36(4), 296-303. doi:10.1579/00447447(2007)36[296:MTSBLF]2.0.CO;2

Knight, L., \& Riggs, W. (2010). Nourishing urbanism: A case for a new urban paradigm. International Journal of Agricultural Sustainability, 8(1-2), 116-126.

Lang, D. J., Wiek, A., Bergmann, M., Stauffacher, M., Martens, P., Moll, P., ... Thomas, C. J. (2012). Transdisciplinary research in sustainability science: Practice, principles, and challenges. Sustainability Science, 7(1), 25-43.

Magnuson-Stevens Fishery Conservation and Management Act, § 3587-3588 (2007).

Manetti, G., \& Becatti, L. (2009). Assurance services for sustainability reports: Standards and empirical evidence. Journal of Business Ethics, 87(1), 289-298.

Monterey County Business Council. (2012). Economic Report.

NOAA - National Marine Fisheries Service. (2014). Commercial Fisheries Statistics. Retrieved from http://www.st.nmfs. noaa.gov/commercial-fisheries/commercial-landings/ annual-landings/index

NOAA Fisheries - West Coast Region. (Summer, 2014). Recent 
Stories. Retrieved from http://www.westcoast.fisheries. noaa.gov/stories/2014/30_06302014_groundfish_catchshares_sustainable.html

Nitkin, D., \& Brooks, L. J. (1998). Sustainability auditing and reporting: The Canadian experience. Journal of Business Ethics, 17(13), 1499-1507.

Reed, M. S., Dougill, A. J., \& Baker, T. R. (2008). Participatory indicator development: What can ecologists and local communities learn from each other. Ecological Applications, 18(5), 1253-1269.

Reed, M. S., Fraser, E. D., \& Dougill, A. J. (2006). An adaptive learning process for developing and applying sustainability indicators with local communities. Ecological Economics, 59(4), 406-418.

Responsive Management. (2007). California Residents' Opinions on and Attitudes Toward Coastal Fisheries and their Management. Harrisonburg, VA.

Responsive Management. (2008). California Tourism and Fishing Heritage Assessment. Harrisonburg, VA.

Sethi, S. A., Riggs, W., \& Knapp, G. (2014). Metrics to monitor the status of fishing communities: An Alaska state of the state retrospective 1980-2010. Ocean \& Coastal Management, 88, 21-30. doi:10.1016/j.ocecoaman.2013.11.007

Waddell, P. (2002). UrbanSim: Modeling urban development for land use, transportation and environmental planning. Journal of the American Planning Association, 68(3), 297-314.

Waddell, P., Ulfarsson, G. F., Franklin, J. P., \& Lobb, J. (2007). Incorporating land use in metropolitan transportation planning. Transportation Research Part A: Policy and Practice, 41(5), 382-410. doi:10.1016/j.tra.2006.09.008

Worm, B. et al. (2009). Rebuilding global fisheries. Science, 325, 578-585. 